\title{
Neutral, risky or provocative? Trends in titling practices in complementary and alternative medicine articles (1995-2016)
}

\author{
Françoise Salager-Meyer ${ }^{1}$ \\ University of The Andes. Mérida. Venezuela
}

Beverly A. Lewin

Division of Foreign Languages, Tel Aviv University, Ramat Aviv, Israel

Marianela Luzardo Briceño

Universidad Pontificia Bolivariana-Bucaramanga, Colombia

\begin{abstract}
This paper analyses the length and titling practices in the under-researched field of complementary and alternative medicine (CAM). Our corpus consisted of 360 articles published between 1995 and 2016 in three CAM journals. The length and frequency of Nominal, Verbal and Question titles were compared across genres and over time. A 40\% overall title length increase was found. Our study confirms that title length is related to genre, research paper (RP) titles being significantly longer than reviews and case report titles. Moreover, RP titles were found to exhibit the greatest length increase over time. In this study, Nominal titles were the most frequent title type in the three genres and over the 20-year period analyzed, although they slightly decreased over time. In contrast, Verbal (full sentence) titles increased over time, especially in RP titles. Question titles were the only type that significantly increased over time, especially in review article titles. These findings were compared with those obtained by previous titleology research on conventional (CONV) medicine paper titles. We conclude that although CAM and CONV are divergent approaches to health care,
\end{abstract}

Corresponding author - Graduate School of Medicine, University of The Andes. Mérida. Venezuela.

Email: francoise.sm@gmail.com 
their titling practices revealed more similarities than differences. These similarities may reflect a growing tendency towards practices associated with popular media to attract readership, such as use of Question and Verbal titles. This competition for attention could have serious implications for health care if the trend increases for clinicians to rely on the titles of relevant articles to make therapeutic decisions.

\title{
¿Neutros, arriesgados o provocativos? Tendencias en las prácticas titulares en artículos de medicina complementaria y alternativa (1995-2016)
}

\begin{abstract}
RESUMEN
En este artículo se analiza la longitud y las prácticas titulares de los artículos en el campo de la medicina alternativa/complementaria (MAC). Nuestra muestra comprende 360 títulos de artículos publicados entre 1995 y 2016 en tres revistas de MAC. La evolución de la longitud y de la frecuencia de los títulos Nominales, Verbales e Interrogativos se compara entre los tres géneros textuales analizados. Un aumento del $40 \%$ en la longitud de los títulos se registró a través del tiempo, lo cual corrobora, por una parte, que la longitud de los títulos depende del género textual, $y$, por otra, que los títulos de los artículos de investigación son significativamente más largos que los de los artículos de revisión y de los informes de caso. Además, la longitud de los títulos de los artículos de investigación aumentó de manera más notoria a través del tiempo que la de los otros dos géneros. En cuanto a los tipos de títulos, nuestros hallazgos muestran que los títulos Nominales son los más frecuentes en los tres géneros estudiados y durante los 20 años analizados, aunque su frecuencia disminuyó a través del tiempo. Por el contrario, la frecuencia de los títulos Verbales aumentó con el tiempo, especialmente en los títulos de artículos de investigación. Los títulos Interrogativos fueron los únicos cuya frecuencia aumentó de manera significativa con el tiempo, especialmente en los artículos de revisión. Se compara los hallazgos del presente estudio con aquéllos previamente encontrados en estudios similares pero llevados a cabo con muestras de títulos tomados de artículos de medicina convencional/alopática (CONV). Concluimos que, a pesar de que la MAC y las CONV representan dos enfoques terapéuticos distintos, sus prácticas titulares revelan más similitudes que diferencias. Esas similitudes pueden reflejar una tendencia cada día más acentuada hacia prácticas asociadas con aquéllas de los medios de prensa popular para atraer el lector, tal como es el uso de títulos Verbales e Interrogativos. Ese afán de atraer la atención del lector podría tener implicaciones serías en el cuidado de la salud si sigue en aumento la tendencia (ya notada) de los médicos clínicos de tomar decisiones terapéuticas en base a los títulos de los artículos médicos.
\end{abstract}

Palabras claves: análisis del discurso, títulos, medicina complementaria/alternativa, medicina convencional/alopática, diacronía 


\section{Introduction}

A title represents the point from which readers decide whether a text is worth reading or not, in the same way as do trailers of movies (Eva 2013). In Sword's (2012) metaphorical parlance: "Like a hat on a head or the front door to a house, the title of an academic title offers a powerful first impression."

In the early 1990's, Salager-Meyer (1991) argued that, because of the tremendous growth in the number of journals, hence of publications, and because of the interdisciplinary nature of research, scientists would have to rely more on abstracts as concise, complete and accurate sources of information. But research indicates that, almost thirty years later, the tendency seems to be for scientists to rely on titles only in selecting papers relevant to their research. Mabe and Amin (2002), for example, found that scientists read on average 97 articles per year, twice as many abstracts (204), and 10 times as many titles $(1,142)$. Similarly, Lowes (2016) reports that most PubMed users do not read beyond the abstract, while Kerans et al. (2016) assert that today's clinical researchers are content with reading the title only before discarding the article. Even more surprising is evidence that doctors sometimes make clinical decisions based only on the titles of journal articles (Haynes et al. 1990; Goodman 2000). Thus, titles and abstracts are considered the two most important parts of a paper (Fox and Burns 2015; Vodanovic 2015). Furthermore, according to Mateen et al (2013), for online-searches, a titles-first approach is not only more efficient than a traditional titles-plus-abstract approach but it also yields the same reference results. What is more, the more precise and accurate a title is, the easier it will be for bibliographers to compile data for indexing, abstracting, searching and retrieving information (Hodges 1983; Diodato and Pearson 1985). This is crucial because data retrieval systems almost exclusively operate on the basis of titles and abstracts

This explains why the field of titleology has grown substantially in the last three decades or so and has been addressed from a heterogeneous range of perspectives, mostly by applied linguists (e.g. Soler 2007, 2011; Salager-Meyer et al. 2013; Méndez et al 2014), and information scientists (Yitzhaki 1994 1997, 2002; Jamali and Nikzad 2011), among other fields. Another group, mostly composed of editor physicians, has been interested in determining whether the construction and length of an academic title have a significant impact on citation rate Jacques and Sebire 2010; Habibzadeh and Yadollahie 2010; Jamali and Nikzad 2011; Fox and Burns 2015; Letchford et al. 2015). Research on this particular issue yielded conflicting results, thus underscoring the need for more work in that area. 
Although there is abundant research on titleology, to our knowledge no study has been conducted on complementary and alternative medicine (CAM) titles. In fact, as a whole, CAM discourse is under-researched, especially when compared with the amount of research conducted on the discourse of allopathic/conventional medicine, herein referred to as CONV medicine. (For an overview of the research carried out on allopathic medicine discourse, see Salager-Meyer 2014; and Ferguson $2015)^{2}$.

This lack of interest is surprising in the face of increasing interest in CAM worldwide since the early 1990's (Sharma 2000; Gale and McHale 2015). Bishop and Lewis (2008), for example, report that $46 \%$ of the UK population can be expected to use one or more CAM therapies in their lifetime. In addition, CAM therapies (especially chiropractic manipulation, homeopathy and acupuncture) are attracting increased attention. Frass et al. (2012) point out that the number of physicians with specific training in CAM therapies is continually growing.

In view, then, of the importance of academic paper titles, on the one hand, and of CAM, on the other, and because scant linguistic research has been conducted on CAM discourse, we hope to try to fill that conceptual gap by presenting here the results of a diachronic analysis of a corpus of titles from CAM articles published between 1995 and 2016 (see 'Corpus' below). We then compare our findings with previous titleology research, especially studies that focused on CONV paper titles. As the first step, we deal with length and title type in a corpus of titles drawn from the three main professional medical genres (Jamali and Nikzad 2011; Gotti 2016): two primary genres (research articles, the most highly prized genre among general practitioners and specialist clinicians, and case reports), and one secondary genre (review and systematic review articles).

\section{Corpus and methods}

\subsection{Corpus}

We decided to focus on CAM papers published in CAM journals because we assumed that the titles of CAM papers published in CONV journals would conform to the norms established in CONV guidelines.

Of the 50 CAM journals listed in the SCImago Journal and Country Rank (2014), we selected the three journals whose titles included the words "complementary",

2 To our knowledge, our research group on scientific discourse analysis at the University of The Andes is the only one that has shown interest in CAM discourse (e.g. Salager-Meyer et al. 2014). 
"alternative" and "medicine". We chose these titles in order to select CAM journals with the widest coverage/audience possible and to exclude specialist journals that would focus on, for example, acupuncture, or natural products. The three journals then selected were: The BMC Journal of Complementary and Alternative Medicine" (BMC CAM), Journal of Alternative and Complementary Medicine (JACM), both launched in 1995, and Evidence-based Complementary and Alternative Medicine (E CAM), launched in 2004.

Regarding title selection, in both JACM and BMC CAM, we chose the first five research paper (RP) titles in the first issue of each volume in each year (e.g., 1995, Volume 1, January) from the launching date of the journal till the first issue of January 2016. All these were regular and not special guest-edited issues. Because the other genres -- review articles, systematic reviews/ meta-analyses (both abbreviated herein as RV) and case reports (CR)-- were much less numerous than $\mathrm{RP}$, we included all the RV and CR titles in each of the first issues of each volume from the launching date of the journals till January 2016.

As for E CAM, as there were very few articles in the first two volumes, i.e., 2004 and 2005, we were able to include all the RP, RV, and CR published in these volumes. When, however, more than 5 articles of each genre began to appear per volume in 2006, we chose the first 5 articles of each genre. (By 2014, as many as 5,182 articles were published.). ${ }^{3}$

This yielded a corpus of 360 titles, the journal and genre distribution of which is displayed in Table 1. We consider that our corpus size is large enough since, as Kerans et al. (2016) point out, sampling regular issues to harvest 70 titles is adequate to reflect a journal practice.

\begin{tabular}{lllll}
\hline CAM Journal & RP & RV & CR & TOTAL \\
\hline Evid-Based CAM (2004-2016) & 61 & 62 & 3 & 126 \\
\hline J ACM (1995-2016) & 66 & 24 & 15 & 105 \\
\hline BMC CAM (1995-2016) & 80 & 43 & 6 & 129 \\
\hline \multirow{2}{*}{ TOTAL } & $\mathbf{2 0 7}$ & $\mathbf{1 2 9}$ & $\mathbf{2 4}$ & $\mathbf{3 6 0}$ \\
& $(57.5 \%)$ & $(35.8 \%)$ & $(6.7 \%)$ & \\
\hline
\end{tabular}

Table 1. Corpus size per journal and genre.

3 The determination of genres was problematic. First of all, each journal has its own label for research articles (e.g., 'original articles') or the author's own title did not match what was actually in the article. In many cases, articles were not published in the appropriate sections, especially till 2010. In unclear cases, we read the paper abstract so as to determine its genre. 


\subsection{Variables and methods}

One continuous variable (title length) and three categorical (Yes/No) variables that corresponded to the three main genres (see below) were recorded for each title.

So as to calculate the length of each of the 360 titles making up our corpus, we counted all the function and content words included in each title. The concept of "word" was defined as the unit occurring between spaces, except for two cases: compound words such as 'in vitro' were considered one word. Conversely, each word represented in an acronym was counted separately, so that e.g. "MRI" was counted as three words (magnetic resonance imaging). As for hyphenated words, each constituent was counted as one word only when the first element was an independent word, e.g., 'placebo-controlled' was counted as two words.

Then, we analyzed the title types: Nominal, Verbal, and Question titles. A Nominal title, also called "indicative" (Huth 1990: 90; Goodman 2000: 914) or "descriptive" (Fischer and Zigmond 2004), is neutral in the sense that it simply states the topic of the article (example 1).

The clinical effectiveness of healing touch (JACM/RP/2002) ${ }^{4}$

In contrast, a Verbal title consists of a complete sentence (example 2 below). Other researchers have assigned different labels to this title form. Contrary to descriptive/Nominal titles, which are neutral, as we just said, Verbal titles generally reveal a conclusion claim about the most robust research finding.

Therapeutic horse riding improves cognition, mood arousal, and ambulation in children with dyspraxia. ( ACM/RP/2014)

An analysis of the main semantic and grammatical features of Verbal titles (e.g. type of verbs, and tense) was conducted (below).

The last category of titles we analyzed corresponds to Question titles, i.e. those titles that formulate a question either in a nominal way (example 3) or in a verbal way (example 4):

Goal-directed acupuncture in sports: Placebo or doping? (E CAM/ RP/ 2011)

(4) Does the consumption of green tea reduce the risk of lung cancer among smokers? (E CAM/RV/2007)

All the examples are drawn from our CAM corpus. Journal name, paper type, and year of publication are indicated in parentheses, and the variable presented and discussed is in italics. 
So as not to record Question titles under two different categories (both 'Question' and 'Nominal' or both 'Question' and 'Verbal'), both types of Question titles (nominal and verbal) were recorded as 'Question titles' only.

The above-mentioned variables were coded independently by the first two authors (FSM and $B L$ ), and three EXCEL spreadsheets were created, one for each journal. Upon completion of the coding of the 360 titles, the statistician (co-author MBL) combined the three spreadsheets into one. So as to conduct the diachronic analysis of our data, MBL divided our corpus of 360 titles into two Blocks: Block A made up of the titles published between 1995 and 2005, and Block B that comprised those published between 2006 to 2016.

The statistical analysis of our quantitative findings was carried out by means of ANOVA tests and difference between proportions through normal distribution through t-student distribution. In both cases, the Minitab -16 statistical package was used. Differences were considered statistically significant at a level of $p<0.05$ and are expressed in this paper to four decimal places unless they approach 0 or 1 , in which case approximate values (e.g. <0.0001) are given.

\section{Results and discussion}

\section{General considerations}

We found that the latest available guidelines to authors regarding the form or content of titles give either no (E CAM) or very few instructions, e.g. "the title should include, if appropriate, the study design" (BMC CAM, 2016) and "the title should clearly define the purpose of the paper and be brief" (JACM, 2015)

These vague guidelines of the 3 CAM journals in our corpus stand in sharp contrast to those of CONV medicine journals in that the latter tend to be more specific, asking authors, for example, not to use overly general titles, declarative or question titles for scientific manuscripts (e.g. Journal of the American Medical Association) and to write titles that include information that, along with the abstract will make electronic retrieval of the article sensitive and specific (The New England Journal of Medicine, Annals of Internal Medicine).

Below we present quantitative findings on length and title types both globally and per genre, and from a diachronic perspective. Moreover, since few differences were found across journals, the synchronic and diachronic behavior of the variables analyzed will, unless otherwise specified, refer to the results obtained from the three journals together. 
Now, regarding CR titles, as Table 1 shows, they account for only $6.7 \%$ only of our corpus. This is due to the fact that, as we argue elsewhere (Salager-Meyer et al. 2013), CRs have come under scrutiny and disfavor among some members of the medical scientific community who consider them irrelevant because they add little to everyday medical practice (Yadav 2006). Be that as it may, because of their very small number in our CAM corpus, our findings regarding this genre will reflect tendencies only, which, as such, should not be generalized.

\section{1. Length}

Table 2 displays the total number of words as well as title average length in the whole corpus ( 14 words) and in each genre. It can be seen that the average title length differs among genres $(p=0.02)$. However, the only significant genre difference was found between RP title length and RV title length $(p=0.001)$.

\begin{tabular}{lll}
\hline Genres (N titles) & Number of words & Average length \\
\hline $\operatorname{RP}(207)$ & 3.058 & 14.8 \\
\hline $\operatorname{RV}(129)$ & 1664 & 12.9 \\
\hline CR $(24)$ & 332 & 13.8 \\
\hline TOTAL (360) & $\mathbf{5 . 0 5 4}$ & $\mathbf{1 4}$ \\
\hline
\end{tabular}

Table 2. Total number of words and average title length in the whole corpus and in each genre.

This cross-generic difference in title average length corroborates the findings of previous research on scholarly article titles in CONV medicine and in related disciplines, where RP titles have also been found to be longer than those in RV (Soler 2007, 2011; Wang and Bai 2007; Kerans et al. 2016), and in CR (Salager-Meyer et al. 2013). It should be pointed out, though, that titles of papers published in highly prized, elite CONV general medicine journals (e.g., the NEJM and the British Medical Journal) were found to be shorter than those of articles published in less prestigious specialist journals (Kerans et al. 2016).

In sum, title length is related to genre, RP titles from both CAM and CONV medicine being longer than those of RV and CR; apparently RP authors tend to include more up-front information in their titles than do RV and CR authors. This genre-related difference may be in part attributable to the different communicative function of each genre (Soler 2011), insofar as RP authors need to stress their own contribution to knowledge. Additional relevant words, of course, add to the probability of such articles being retrieved electronically by researchers in the same field. This, however, will have to be confirmed by further research.

The use of Verbal titles (i.e. titles that form a complete sentence) - more frequent in 
both CAM and CONV medicine RP than in RV titles, as we will see further (Section 3.2.3 below) - also might explain the greater length of RP titles. Indeed, research has shown that Verbal titles are longer than Nominal ones (Lewison and Hartley 2005; Jamali and Nikzad 2011). Example 5 following is an excellent illustration of a content packed 'mini-abstract' RP title that loads a lot of bottom-line information into the most highly foregrounded part of the article: the title. The three conjugated verbs in italics succinctly present the conclusions of the research:

Qigong exercise alleviates fatigue, anxiety, and depressive symptoms, improves sleep quality, and shortens sleep latency in persons with chronic fatigue syndrome-like illness (E CAM/RP/ 2014)

Interestingly, the comparison between our findings on title length in CAM papers and those of previous research in CONV medicine papers also indicates that, regardless of genre, CAM paper titles tend to be longer than those of CONV medicine papers, and the difference is even more pronounced when we examine 2016's data (see Section 3.2.2 below). This difference could be due to the stricter and more detailed title guidelines in CONV medicine journals referred to earlier, the latter having a much longer history of research reporting; the BMJ, for example, was launched in 1840.

We also believe that the greater length of CAM titles could be accounted for by the fact that CAM titles quite frequently provide the plant Latin names and the descriptions of their substances, as example 6 clearly illustrates:

(6) Evaluation of acute 13-week subchronic toxicity and genotoxicity of the powdered root of Tongkat Ali (Eurycoma longifolia Jack) (E CAM/RP/2013)

Now, an analysis of our data from a diachronic standpoint (Graph 1) shows that, overall, the average length of the 360 titles (all genres combined) increased significantly from 11.75 words in 1995 to 16.45 words in 2016 ( $p=0.001$ ). This represents a $40 \%$ increase in title length over the 20 -year span analyzed here. 


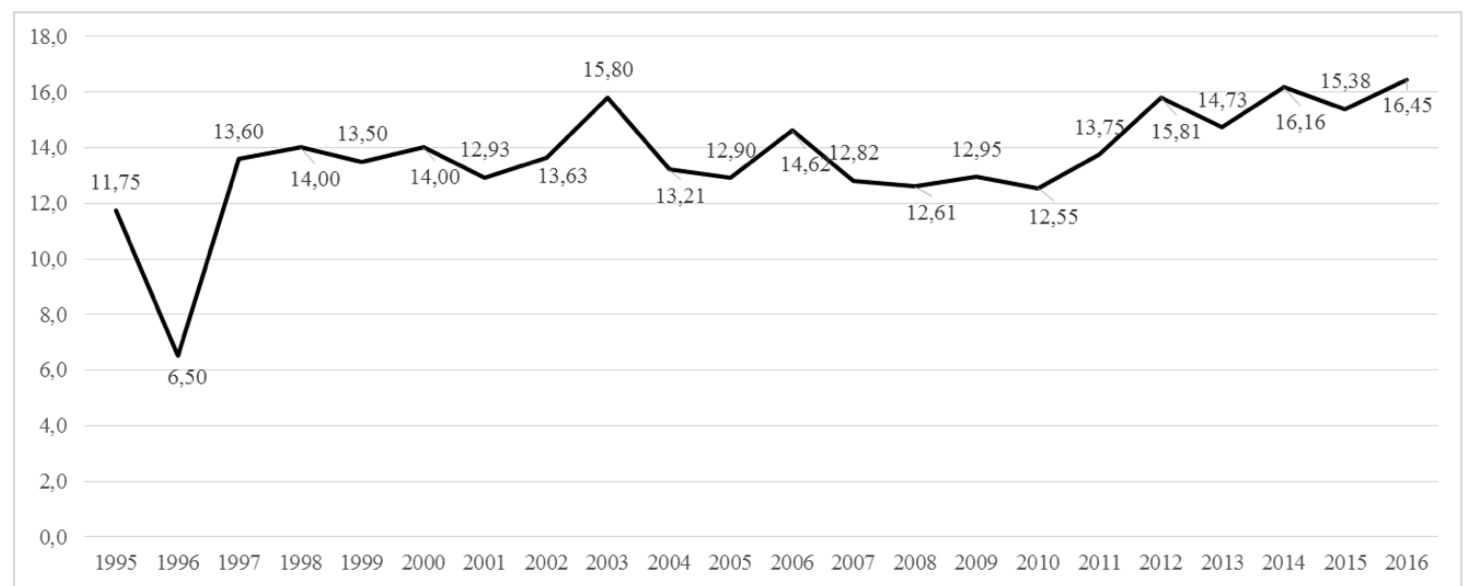

Graph 1. Length evolution of the 360 CAM titles (1995-2016), all genres combined.

But if we discriminate the evolution of our 360 CAM title length per genre (Graph 2), then, we get a different picture.

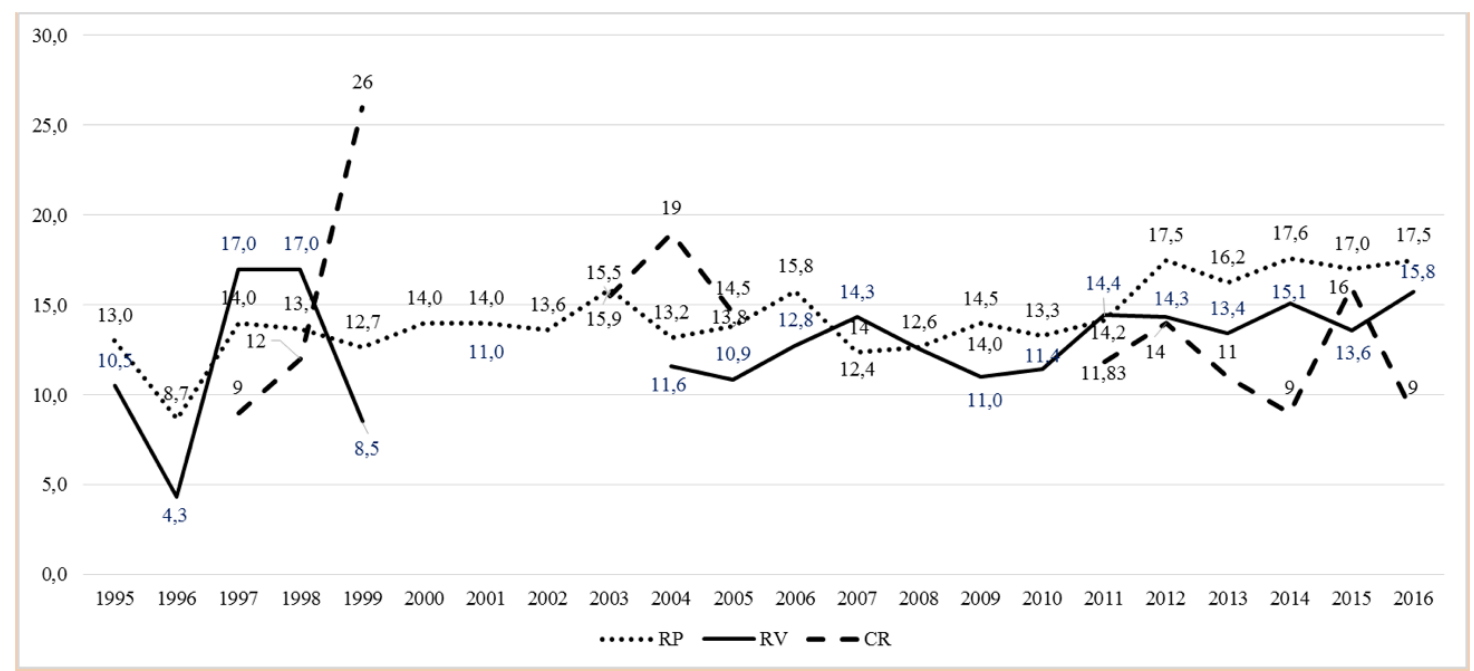

Graph 2. Length evolution of the 360 CAM titles per genre (1995-2016)

Indeed, as Graph 2 clearly shows, RP titles exhibit the most constant length increase, from 13 words per title in 1995 to 17.5 in $2016(p=0.038)$, which represents approximately a 35\% increase in the number of words making up RP titles over this 20-year time span. Regarding the evolution of the length of RV titles, it exhibits a somewhat erratic up-and-down behavior between both 1995 and 1999 and between 2004 and 2009, but then, from 2010 till 2016, it shows a constant increase, very 
similar to, though somewhat lower than, that exhibited by RP titles (from 11 words in 2010 to 15.8 words in 2016, p= 0.001). As for CR titles, Graph 2 indicates not only that their behavior is the most erratic of all, but also that they are the only genre that exhibits a length decrease over time, albeit borderline $(p=0.045)$.

Now, the only research that examined the evolution of title length in a genre different from RP and RV is Salager-Meyer et al.'s (2013) study on CONV medicine CR titles published between 1840 and 2009. Their study indicates that CR titles increased in length over time, a finding that cannot be supported at the present time because of the small number of CR titles analyzed (24 in total, viz. 6.7\% of the total number of our corpus titles).

Our findings on the evolution of title length in CONV medicine RP titles, too, are in line with those of previous research. For example, Lewison and Hartley (2005) reported a 125\% increase in title length in the periods 1970-1974 and 2005-2009, and Goodman (2011) found an approximate doubling of title length since the 1970's.

Our research on grammatical complexity (in progress) indicates that along with the pronounced increase in the number of words in these titles, information load and semantic richness of RP and RV titles from both CAM and CONV medicine have also increased over time. These last two characteristics are the result of a tendency towards greater lexical density, i.e., packing more information into fewer words by increasing the number of content words and reducing the number of function words. In this process, simple verbs are transformed into past participles (-ed forms) as shown in example 7, and present participles (-ing forms, not shown here).

\section{Allium hookeri root protects oxidative stress-induced inflammatory responses and $\beta$-cell damage in pancreas of streptozotocin-induced diabetic rats (BMC CAM/RP/2016)}

\subsection{Title types}

\section{2. 1. Title types in the whole corpus and diachronically (all genres)}

Graph 3 shows that, in the whole corpus, Nominal titles (which simply state the topic of the article without forming a sentence) significantly outweigh both Verbal and Question titles ( $p=0.000$ in both cases), and that Verbal titles are significantly more frequent than Question titles $(p=0.010)$.

Comparing the evolution (Block A vs. Block B) of each title type, Graph 3 shows that, although Nominal titles remain by far the most frequent title type in both Blocks, their frequency slightly (but not significantly) decreased over the period studied. As 
for Verbal titles, their frequency slightly (but not significantly) increased from Block A to Block B. Moreover, in Block A, Verbal titles significantly outweigh question titles ( $p$ $=0.016$ ), but that difference is no longer significant in Block B. Interestingly, as Graph 3 shows, the only title type that exhibits a significant increase over time is the Question title type $(p=0.019)$.

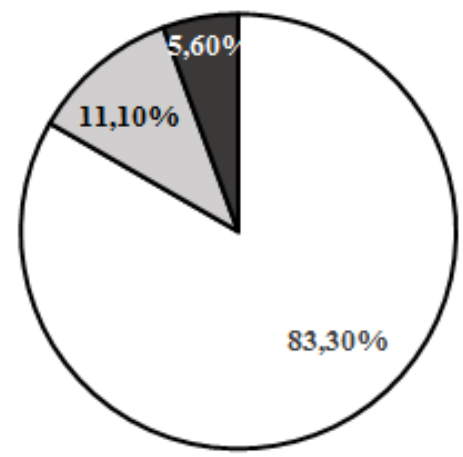

In the whole corpus

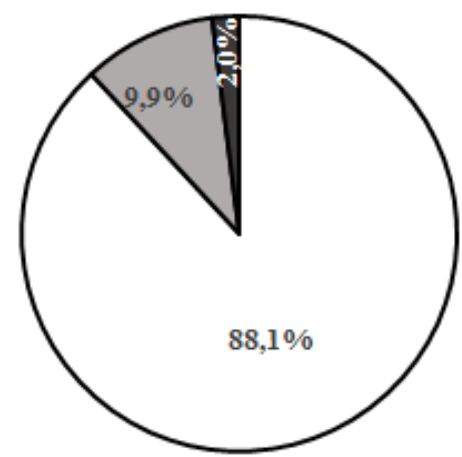

Block A

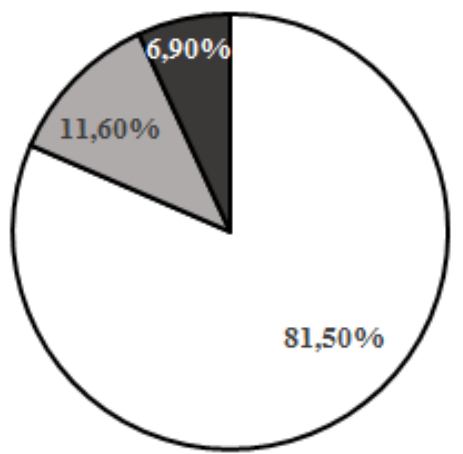

Block B

Graph 3. Title types in the whole corpus and diachronically.

\subsubsection{Title types in the whole corpus by genre}

As Graph 4 shows, in the three genres Nominal titles are, by far, the most frequent title type (over $80 \%$ of the 3 title types). They are also significantly more frequent in RV than in RP $(p=0.039)$.

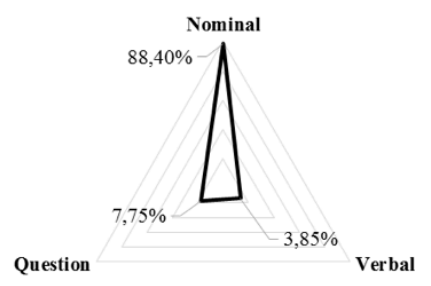

RV

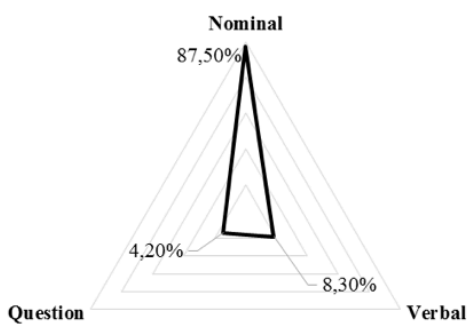

CR

Graph 4. Title types per genre in the whole corpus. 
Graph 4 also indicates that in RP, Verbal titles are three times more frequent than Question titles $(p=0.000)$, whereas in RV titles, Question titles outnumber Verbal titles. Verbal titles are also significantly more frequent in RP than in RV ( $p=0.002)$. As for CR titles, Graph 4 shows that, although Verbal titles are also more frequent than Question titles, the difference is not statistically significant.

\subsubsection{Evolution of title types per genre}

According to Graph 5, both in Block A and Block B and in the three genres, Nominal titles by far outweigh Verbal and Question titles, although they significantly decreased over time in both RP and in CR ( $p=0.039$ and 0.053 , respectively).

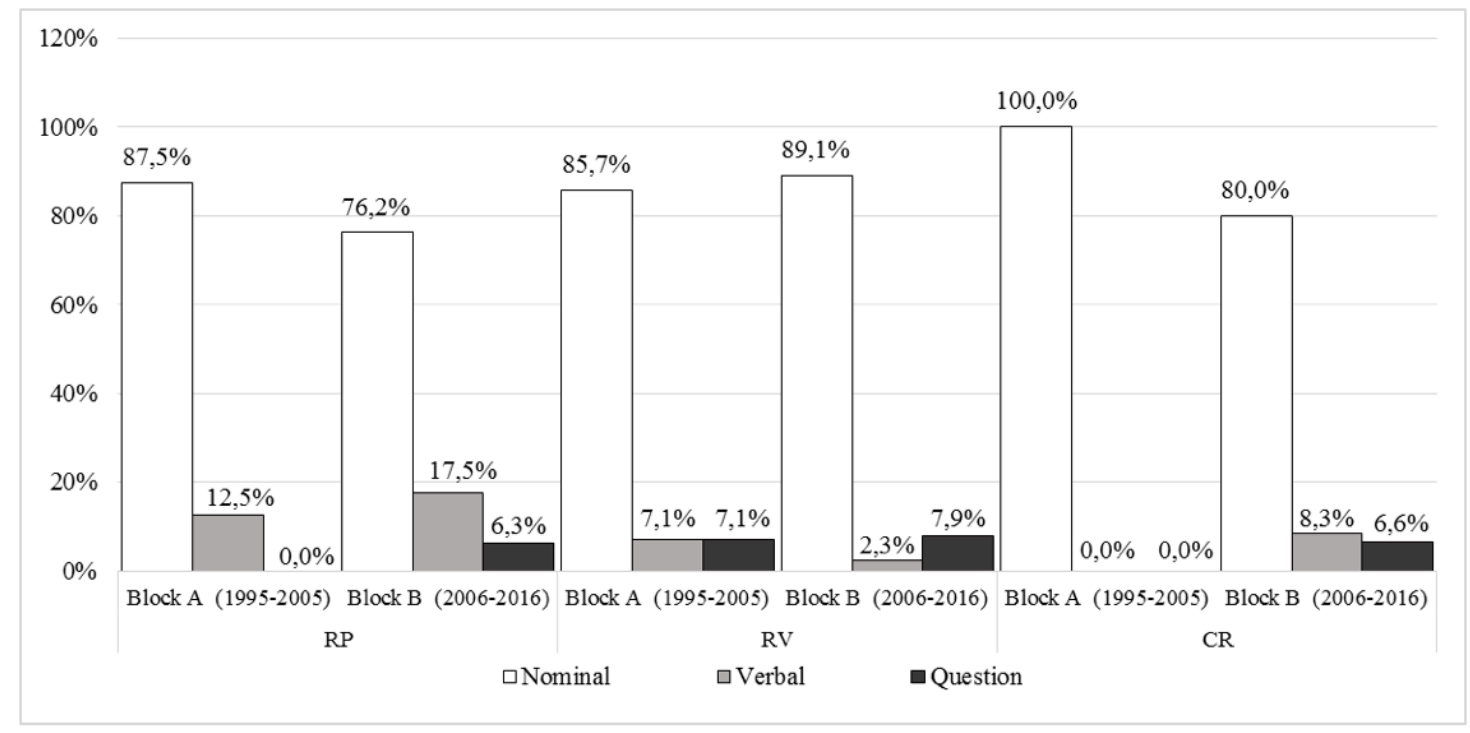

Graph 5. Title types per genre over time.

Graph 5 also reveals that the frequency of Verbal titles decreased over time in RV titles; in contrast, it increased in both RP and CR, but the difference between the frequency recorded in Block $A$ and that recorded in Block $B$ was found to be statistically significant in CR only $(p=0.007)$. As for Question titles, they significantly increased over time in RP ( $p=0.002)$ and in CR $(p=0.05)$, but not in RV.

\section{Nominal titles}

Our results on title types are consistent with those of previous titleology research that also found a marked preponderance of Nominal over Verbal and Question titles. For example Busch - Lauer (2000), recorded a much greater frequency of 
Nominal titles in a corpus of German and English (CONV) medicine RP titles, as did Haggan (2004) in RPs from other disciplines (linguistic, literature and science). Likewise, Soler (2007) found that 72\% of the English-medium RP and RV article titles she analyzed in biology belonged to the Nominal group. Along the same lines, in a corpus of 417 research article titles from the NEJM published between 2003 and 2005, Wang and Bai (2007) reported that $99 \%$ of these titles were of the Nominal type.

Although the frequency of the Nominal title construction slightly decreased over time in our sample of CAM titles -- especially in RP and CR--, its sustained prevalence in the three article genres over the 20-year span covered by the present research reflects the lexically dense style that typifies CAM and CONV medical discourse. Not surprisingly, the Nominal construction as shown in example 8 from our corpus is the one most frequently recommended by (English) scientific writing advisory manuals (Day 1998; Goodman and Edwards 2014):

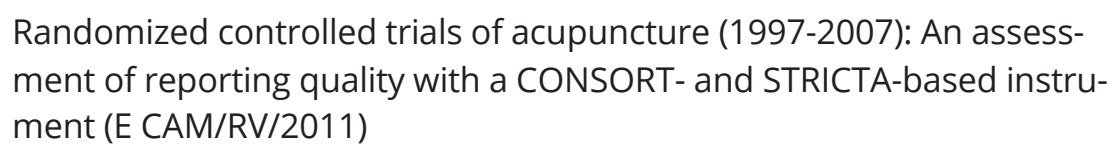

\section{Verbal titles}

Regarding Verbal (full sentence) titles, our findings show that 1) overall (i.e. in the whole corpus), they represent $11.1 \%$ of all titles and are significantly more frequent than Question titles, 2) they increased over time, and 3) they are much more frequent in RP than in RV and CR titles. In part (see below), this, too, is consistent with the results of previous titleology research that has underlined a shift over time towards a greater frequency of full - sentence/Verbal RP titles, which have been associated with higher citation rates (Paiva et al. 2012). By the end of the $20^{\text {th }}$ century, Berkenkotter and Huckin (1995), for instance, reported that titles of RP had become more informative over time. Their research showed that in the 1970's, full sentence titles were very rare, but that in the mid-1990s, they made up more than $20 \%$ of all journal articles and were especially common in biology, a non-clinical discipline. A greater frequency of Verbal titles in biology RP (51\%) than in CONV medicine RP titles (16\%) was also reported by Soler (2007).

In addition to field, there seem to be variations in Verbal titles according to type of journal. An increasing number of Verbal titles was also found in the multidisciplinary journal Nature in which almost a quarter of titles of the RP published in the 1990's and the early $21^{\text {st }}$ century anticipate the research conclusions, especially in molecular and developmental biology, thus adopting a journalistic style Jaime-Sisó 2009). Not so, however, in the other multidisciplinary journal Science, where only a 
few RP titles were found to be Verbal (Jaime-Sisó 2009). Still another inter-journal variation was reported by Kerans et al. (2016), who observed a significant difference in the frequency of Verbal titles between highly ranked general clinical medicine (e.g. The NEJM and The Lancet) and (sub)-specialist journals, the former using far fewer Verbal titles than the latter. The authors cogently argue that the two specialty journals they examined publish both clinical and bench research, and that authors' familiarity of the Verbal title form in bench research could influence the choice of that title form in clinical research titles. That straightforward conclusions can be more readily reached in animal/bench research than in clinical research on humans could then explain the difference observed in the frequency of Verbal titles in medical research.

The question of tense choice in Verbal titles is relevant, since we know that with the choice of the present tense, the authors stress the general validity of their research results. Goodman $(2000,2010)$, too, asserts that CONV general medicine RP titles are becoming more informative, with the present simple the dominant tense of the main verb. His research also shows that the increasing use of the present tense in RP titles is even more pronounced in core clinical journals: on average a 105-fold increase in such journals compared with a $43 \%$ increase in lesser quality journals, despite some criticism of its use. Be that as it may, that the use of Verbal titles in scientific writing is a generic question (Soler 2011) is undoubtedly confirmed by our research on CAM titles.

A closer look at the verbs most frequently used in our Verbal titles (Table 3, next page) reveals interesting semantic and grammatical features.

a) Type of verbs: The verbs used are all research related or, to use our term, "effectproducing" verbs. Improve is by far the most common lexical verb, in our CAM sample both in Block $A$ and in Block $B$, but with a greater frequency in the latter. Interestingly, improve, inhibit and ameliorate - the verbs most frequently recorded in our CAM corpus -- were also those most frequently encountered in a sample of PubMed (CONV medicine) clinical trials (Goodman 2000 and 2010). According to Goodman (2010), 2\% of titles from articles classified as clinical trials by PubMed $®$ included one of seven active verbs, eliminates, abolishes, prolongs, prevents, predicts, reduces and improves. Among these, only prevents (example 9) improves, and reduces were found in our corpus: 


\begin{tabular}{|c|c|c|}
\hline & Block A (1995-2005) & Block B (2006-2016) \\
\hline $\mathrm{RP}$ & $\begin{array}{l}\text { Improved* } \\
\text { improve } \\
\text { [Does not] alter } \\
\text { Induces } \\
\text { Inhibits } \\
\text { [Are] mediated by } \\
\text { produced } \\
\text { Reduces }\end{array}$ & $\begin{array}{l}\text { Improve (5) } \\
\text { Inhibits (4) } \\
\text { [Is] related to (3) } \\
\text { Ameliorates (2) } \\
\text { Decreases (2) } \\
\text { Shows (2) } \\
\text { Antagonizes } \\
\text { Attenuates } \\
\text { Alleviates } \\
\text { [Are] associated [with] } \\
\text { Contains } \\
\text { Counteracts } \\
\text { Enhances } \\
\text { Facilitates } \\
\text { Prevents } \\
\text { promotes } \\
\text { Protects } \\
\text { Reduce } \\
\text { Regulates } \\
\text { shortens }\end{array}$ \\
\hline $\mathrm{RV}$ & [Is] represented & $\begin{array}{l}\text { [May] influence (2) } \\
\text { enhance }\end{array}$ \\
\hline CR & & $\begin{array}{l}\text { [May be] contraindicated } \\
\text { induced }\end{array}$ \\
\hline
\end{tabular}

Table 3. List of verbs found in CAM Verbal titles per genre and Block.

* The figure in parentheses indicates the number of times we found the verb in the corpus, not the number of titles in which these verbs were recorded. When no figure is mentioned, it means that the verb was found only once.

b) Polarity (Positive/negative): All but one of the sentences in which these verbs appear are affirmative, thus confirming that bias exists in favor of positive (significant difference) findings (Teixeira da Silva 2015). ${ }^{5}$ We found only one example of a negative result title in our sample ${ }^{6}$. It was recorded in Block $A$, perhaps suggesting that today's CAM researchers overwhelmingly favor present tense and positive sentences when writing their Verbal RP titles.

$5 \quad$ It is well known indeed that negative results are more difficult to publish and that editors have a greater interest in publishing results that can immediately change clinical practice. Negative studies can nonetheless be published by making clear the importance of the negative results being reported (Antonelli and Mercurio 2009; Song et al. 2010).

$6 \quad$ "Kefir consumption does not alter plasma lipid levels or cholesterol fractional synthesis rates relative to milk in hyperlipidemic men: a randomized controlled trial. (BMC CAM/RP/2002)." 
c) Tense: As Table 3 clearly shows, $87 \%$ of the verbs are conjugated in the present tense, by which, as noted above, the authors stress the general validity of their research results. This is clearly illustrated in example 5 (repeated below), which contains three verbs conjugated in the present tense that emphatically convey the research conclusions:

Qigong exercise alleviates fatigue, anxiety and depressive symptoms, improves sleep quality, and shortens sleep latency in persons with chronic fatigue-like illness (E CAM/RP/2014)

In contrast, use of the past tense restricts the claim made in the title to the specific study reported and avoids making extravagant claims about all cases (Salager-Meyer 1994; Lewin 2010). However, as we see in Table 3, this corpus yielded only three instances (one of which is reproduced in example 10) in which the authors use the more restrictive past tense, thereby hedging their conclusions. In the third case (not shown), the past tense is obligatory since it referred to research on only one patient.

Fibromalgya syndrome improved using a mostly raw vegetarian diet: an observational study (BMC CAM/RP/2001)

Similarly, in their analysis of 279 titles of CONV medicine titles, Kerans et al. (2016) also recorded only one instance of a past tense title.

d) Epistemic modality: Epistemic modal verbs such as 'may' express 'uncertainty' about the claim being made. Out of 46 instances of verbs (Table 3), only three were modalized. Two of these corresponded to the same RV title whose results were reported in two parts (example 11 below) and the third one was a CR title, in which past tense is obligatory since only one patient was involved. The almost total absence of modal verbs in Verbal titles again indicates that the authors are presenting their research claims as unquestionable 'facts' (Lewin, 2001, 2005; Salager-Meyer 1994).

Humor and laughter may influence health. I. History and background (E CAM /RV/2006)

Our findings about the preponderance of present tense and almost total lack of modality in CAM Verbal titles point to a tendency for authors to make the strongest claims possible about their results when using Verbal titles for their papers.

\section{Question titles}

The third and last title type analyzed in the present research refers to Question titles, 
which is the least frequent type in our CAM corpus but, which, at the same time, was found to show the greatest increase over time. As a matter of fact, it is the only title type of which the global frequency significantly increased (an almost fourfold increase) over the 20-year span covered by our study.

The overall low frequency of Question titles recorded in our CAM corpus confirms Kerans et al.'s study (2016) that reported an extremely low frequency $(<2 \%$, i.e. three times lower than the prevalence in our CAM corpus) of Question titles in their analysis of article titles from two CONV general medical journals (the NEJM and the BMJ) and two sub-specialty (anesthesiology) journals. The different nature of the journals examined in Kerans et al.'s research can account for the difference observed. The much greater frequency of Question titles observed in our CAM corpus can also be explained by the fact that CAM research is almost in its infancy when compared to Kerans' corpus of CONV medical research; as a consequence, we can speculate that unresolved issues are much more numerous.

From a cross-generic perspective, our findings reveal that it is in RV titles where the frequency of Question titles was the highest, both in Block A and in Block B, but our findings also show that Question titles are increasingly being used today in RP and CR titles. As our quantitative data indicate, Question titles also increased over time in $\mathrm{RV}$ but not as much as they did in RP. From a genre perspective, then, we can assert that, contrary to RP titles (in which Verbal titles were significantly more frequent than Question ones), RV titles exhibit a greater frequency of Question titles over Verbal ones.

This finding is consistent with previous titleology research (Soler 2007; Jamaly and Nizkad 2011; Kerans et al. 2016) that points out that interrogative titles are more acceptable for RV than for RP articles. Nonetheless, interrogative titles are generally frowned upon (Day 1998; Gustavii 2008), and Mayer (2009), in his guidelines on how to write a review article, explains that interrogative titles should only be used when the question asked remains unresolved at the time of the publication. ${ }^{7}$

As for the evolution of Question titles, the increase in their use disclosed by our research confirms Ball's large scale study (2009) on nearly 20,000,000 scientific articles that appear in Scopus in physics, life sciences and medicine published between 1966 and 2005. Indeed, over these 40 years, Ball found a significant increase from $50 \%$ to over $200 \%$ in the number of articles with an interrogative title.

A closer look at the 18 Question titles in our CAM sample reveals some interesting features. A caveat, however: since our sample is quite small, the features mentioned

7 It would have been very difficult -if not impossible -- for us to check whether this was the case of our CAM Question titles. 
here below reflect tendencies only.

Some of the more provocative titles in our corpus were presented as questions, such as:

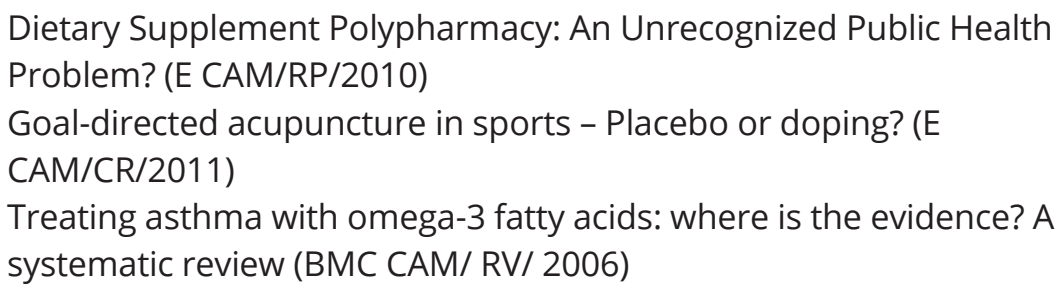

Nominal Question titles represent only 4 of the 18 Questions, but they stand in sharp contrast to the normative grammar used in the entire article and to scientific register in particular, which eschews colloquialisms and deviant forms, as in example 15:

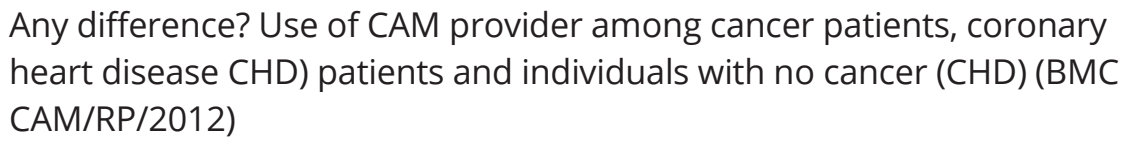

Whether the use of nominal questions is due to the author's desire to save words or to attract the attention of the potential reader is a question for further study.

The predominant form, Verbal Questions, was introduced about equally either by interrogative pronouns, such as who, how, and where), and what (example 16) or by auxiliary verbs to be and to do (example 17 below):

$$
\begin{aligned}
& \text { Who uses CAM? A narrative review of demographic characteristics and } \\
& \text { health factors associated with CAM use (E CAM/RV/2010) } \\
& \text { Is complementary and alternative medicine (CAM) cost effective? A sys- } \\
& \text { tematic review (BMC CAM/RV/2005) }
\end{aligned}
$$

While the majority of Verbal Question titles suggested a definite answer was forthcoming (17 above) only 4 titles were mitigated by the inclusion of an epistemic modal, (might, in 18 below and can in 19) suggesting that the answer might be tentative.

How might acupuncture work? A systematic review of physiologic rationales from clinical trials. (BMC CAM/RV/2006)

Example 19 is an infrequent variant in that it poses two questions simultaneously, the first by means of the interrogative pronoun what and the second through the 
modal can:

What's in a name? Can mullein weed beat TB where modern drugs are failing? (E CAM/RV/2011)

Thus, Question titles, although at present rare in CAM, are increasing in spite of advice to avoid them. The wide array of options for composing these titles may portend future trends.

\section{Conclusions}

The study of medical article titles, and CAM titles especially, has implications for everyone involved in health, be they clinicians, researchers or students. In this paper, the first to focus on titling practices in CAM journals, we examine the evolution of length and title types-- Nominal, Verbal, and Question -- over a 20-year-period.

Concomitantly, the growth of scientific information, a phenomenon for which Alvin Toffler coined the expression "information overload" in 1970, has been inexorable, and clinicians find it more and more difficult to select the most relevant articles within that "avalanche" or "deluge of information" (Fraser and Dunstan 2010: 314). As Haynes et al. (1990) and Goodman (2000), cited earlier, maintain, clinicians may be depending on titles for finding solutions to medical problems; at the same time, there is indeed an almost total absence of CAM journal editorial guidance for writing CAM article titles.

Next, we summarize our general findings and focus on those which might presage tendencies that subvert the objective stance of titles. There is no doubt that titles are getting longer. Overall, our research showed that the average length of CAM titles has increased by 40\% from 1995 to 2016, to an average length of 16.45 words. From a cross-generic perspective, of the three genres analysed here, RP titles were found to be the longest and to exhibit the greatest increase over time. While CAM titles are currently longer than CONV medicine titles, length has increased dramatically also in CONV medicine RP titles. This increase in both approaches to health care could be attributed to the fact that RP authors (unlike RV authors) attempt to stress their contribution to knowledge in the most highly foregrounded part of RP articles. This can be carried to an extreme in Nominal titles to the point that so much bottom-line information is packed into titles that these become mini-abstracts. This may mislead clinicians into thinking that there is sufficient information on which to base a treatment decision and thus, they may avoid reading the relevant abstracts.

We analyzed Nominal, Question and Verbal titles (a sentence that states the main 
research results or conclusion). The Nominal title type predominates in all genres in CAM as well as in CONV medicine, albeit in different proportions. Although CAM Verbal titles comprise only $11.10 \%$ of our total corpus, they were found to have increased over time, to be significantly more frequent than Question titles, and to be especially frequent in the RP genre. Previous research on CONV medicine titles showed that the frequency of Verbal titles is low, especially in highly ranked, elite journals. However, in CONV medicine titles, a shift over time towards a greater frequency of Verbal titles -which, by the way, has been associated with higher citation rates-has been noted as well.

The main verbs found in the CAM Verbal titles displayed four strong tendencies:

- they share the semantic field of 'producing a beneficial effect' (improves);

- they are conjugated in the present tense;

- they are not mitigated by epistemic modal verbs (such as may), and

- they state positive findings.

Along with other authors, we argue that Verbal titles could be misleading because they tend to overgeneralize the results and to insinuate that the conclusions are 'final', thus deterring the reader from searching for later contraindicative evidence. Previous literature has considered verbal titles to be improper, imprudent, and quite frequently, wrong (Rosner 1990). Other authors criticize Verbal titles because of their possible impact on public health, especially if doctors sometimes make therapeutic decisions based on article titles alone. Such "results-claiming titles" can therefore create the illusion that the problem has been solved even if the research conclusion is later contradicted by further research. For this reason, Verbal titles - which, some claim, reflect a commercial marketing tendency-- are actually discouraged by most CONV medicine style manuals (Maisonneuve et al. 2010; Goodman and Edwards 2014).

As for Question titles, they represented only a small percentage (5.60\%) of our corpus but they were the only type that exhibited a significant increase over time. They were moreover found to be particularly frequent in RV. While such titles can actually force the reader to read further, their use is rather alarming to some critics who term them 'suspense arousing', 'sensationalist' or 'provocative'. What is more, some researchers in CONV medicine and other fields argue that Question titles reflect a growing infiltration of a 'journalistic style' or even the influence of commercial 'marketing' tendencies. Ball (2009) mentioned the marketing aspect as one of the decisive factors behind the growing use of Question titles because authors believe questions appeal to readers' curiosity and, therefore, attract them. This opinion is shared by other researchers as well, such as Maisonneuve et al. 
(2010) and Goodman (2011), among others. If so, authors may construct provocative rather than objective titles. Regarding the growing journalistic style of RP titles, Smith (2000: 915) asserts that "the trend is undoubtedly for journals to become more like newspapers and for newspapers to become more like tabloids. It's about readability and trying to grab people's attention in an ever more crowded world."

Finally, the differences observed between CAM and CONV titling practices could stem from the following factors: 1) the way the corpora are compiled, 2), the different journal impact factors, 3) the period covered by the different studies, and 4) the fact that the journals we selected report both clinical and bench research results. Had we selected CAM clinical research only, perhaps our results would have been different.

Recommendations for future research:

- We do not know whether the title composition represents a conscious decision by the authors. It would be interesting to investigate the writers' actual intentions. A representative group of authors could be interviewed about the considerations that inform their titling choices.

- Similarly, it is important to understand precisely which factors attract clinicians. This goal entails real-time interviews of clinicians as they actually do their searches for relevant material.

- We recommend that future research study the impact of the changing titling practices, in particular whether which types of title - Nominal, Verbal or Question -- actually are associated with higher citation rates of the accompanying article.

- We have analysed trends in 3 CAM journals over the last two decades. We detected two trends in our data that could have serious implications. We need a larger sample of Question and Verbal titles to see whether these changes are significant and are increasing.

- This research was based on CAM articles published in CAM journals. Our findings could be compared with titleology practices of CAM papers published in CONV general and/or specialized medical journals.

\section{Acknowledgements}

This research was financed by the University of The Andes Scientific, Humanistic, Technical and Artistic Research Center (CDCHTA-N $\left.{ }^{\circ} \mathrm{M}-1080-16-09-\mathrm{B}\right)$. 


\section{Article history}

Paper received: 09 April 2017

Paper received in revised form and accepted for publication: 16 August 2017

\section{About the authors}

Françoise Salager-Meyer was educated at the University of Lyons, France, and the University of Texas at Austin. She is the author of numerous publications on written medical discourse, mostly from a diachronic, cross-linguistic and crossgeneric perspective. In 1994 and 2004, she was awarded the Horowitz Prize for her works on the pragmatics of written scholarly communication. She was the section editor of the "Language and Medicine section" of the second edition of the Encyclopedia of Language and Linguistics (Elsevier) and is currently coordinating the Research Group on Medical Discourse Analysis (University of The Andes, Graduate School of Medicine, Mérida, Venezuela).

Beverly A. Lewin. Her research has mainly focused on genre analysis and on the interpersonal aspects of scientific discourse. Publications include: Expository Discourse: A Genre-Based Approach to Social Science Texts, with J. Fine and L. Young (2001); Writing Readable Research: A Guide for Students of Social Science (2010); Crossed Words: Criticism in Scholarly Writing, co-edited with F. SalagerMeyer (2011); and Abstract quality in complementary and alternative medicine papers: a structural and cross-generic analysis, with F. Salager-Meyer and María Ángeles Alcaraz Ariza (2014), In Marina Bondi and Rosa Lorès-Sanz (eds.) Abstracts in Academic Discourse: Variation and Change. Bern: Peter Lang. Her articles include Contentiousness in Science: the Discourse of Critique in Two Sociology Journals, TEXT (2005), and, with H. Perpignan, Recruiting the Reader in Literary Criticism, Text \& Talk (2012).

Marianela Luzardo Briceño hold an MA in applied statistics and a PhD in statistics from the University of the Andes (Mérida, Venezuela). She has been teaching statistics at that same Institution in both undergraduate and graduate levels for over twenty years. She has published several articles in applied statistics on artificial intelligence and data mining in international journals. She is currently working at the Universidad Pontificia Bolivariana (Bucaramanga, Colombia). 


\section{References}

Antonelli, M., \& G. Mercurio (2009). Reporting, access and transparency: Better infrastructure of clinical trials. Critical Care Medicine, 37 (1 Supplement), S178-S183.

Ball, R. (2009). Scholarly communication in transition, the use of question marks in the titles of scientific articles in medicine, life sciences and physics. Scientometrics, 79(3), 667-679.

Berkenkotter, C., \& Huckin, T. (1995). Genre knowledge in disciplinary communication, cognition/culture/power. Hillsdale, NJ: Erlbaum.

Bishop. F.L. and G.T. Lewith (2008). Who uses CAM? A narrative review of demographic characteristics and health factors associated with CAM use. Evidence-Based Complementary and Alternative Medicine 7 (1), 11-28.

Busch-Lauer, I. (2000). Titles in English and German research papers in medicine and linguistics. In A. Trosborg (Ed.), Analysing professional genres (pp. 77-97). Amsterdam: John Benjamins.

Day, R. A. (1998). How to write and publish a scientific paper. $5^{\text {th }}$ edition. Cambridge: Cambridge University Press.

Diodato, V. \& K. Pearson (1985). Source indexing in science journals and indexing services: a survey of current practices. Science and Technology Libraries, 6, 103-118.

Eva, K.W (2013). Titles, abstracts and authors. In G. M. Hall (Ed.) How to write a paper, $5^{\text {th }}$ edition. Oxford: John Wiley \& Sons. (pp. 33-41).

Ferguson, G. (2015). English for medical purposes. In B. Paltridge \& S. Starfield (Eds.), The handbook of English for specific purposes. (pp.193-2013). West Sussex, UK: Wiley-Blackwell.

Fischer, B. A., \& Zigmond, M. J. (2004). Components of a research article. Retrieved September 7, 2013, from http,//www2.yk.psu.edu/sites/bee11/files/2011/03/Components-of-a-Research Article.pdf.

Fox C.W. \& C.S. Burns (2015). The relationship between manuscript title structure and success, editorial decisions and citation performance for an ecological journal. Ecology and Evolution. 5(10), 1970-80.

Fraser, A. G., \& Dunstan, F. D. (2010). On the impossibility of being an expert. British Medical Journal, 341, c6815. doi,10.1136/bmj.c6815 21156739

Frass, M, R.P Strassl, H. Friehs, M. Müllner, M. Kundi, \& A. Kaye (2012). Use and acceptance of complementary and alternative medicine among the general population and medical personnel: A systematic review. The Ochsner Journal. 12, 45-56.

Gale, N.K. \& McHale, J.V. (Eds.). (2015) Routledge handbook of complementary and alternative medicine: Perspectives from social science and law. Abington/New York: Routledge.

Goodman, N. W. (2000). Survey of active verbs in the titles of clinical trials reports. British Medical Journal, 320, 914-915.

Goodman, N.W (2010). Novel tools constitute a paradigm, how title words in medical journal 
articles have changed since 1970. The Write Stuff, 19, 269-71.

Goodman, N. W. (2011). Fashion in medicine and language, inferences from titles and abstracts of articles listed in PubMed. The Write Stuff, 20(1), 39-42.

Goodman, N.W., \& M. B. Edwards (2014) Medical writing: A prescription for clarity. $4^{\text {th }}$ edition. NY: Cambridge University Press.

Goodman, R.A, Thacker, S. \& Siegel, P. (2001). What's in a title? A descriptive study of article titles in peer reviewed medical journals. Science Editor, 24 (3), 75-78.

Gotti, M. (2016). Variations in medical discourse for academic purposes In P. Ordoñez López \& N. Edo-Marzá (Eds.). Medical discourse in professional, academic and popular settings (pp. 9-31). Multilingual Matters: Bristol.

Gustavii, B (2008). How to write and illustrate scientific papers. $2^{\text {nd }}$ edition. Cambridge, UK: Cambridge University Press.

Habibzadeh, F., \& Yadollahie, M. (2010). Are shorter article titles more attractive for citations? Cross-sectional study of 22 scientific journals. Croatian Medical Journal. 51(2), 165-170. Doi, 10.3325/cmj.2010.51.165.

Haggan, M. (2004). Research paper titles in literature, linguistics and science: Dimensions of attractions. Journal of Pragmatics, 36, 293-317.

Haynes, R. B., McKibbon, K. A., Walker, C.J., Fitzgerald, N. \& M. F. Ramsden (1990). Online access to MEDLINE in clinical settings. Annals of Internal Medicine, 112, 78-84.

Hodges, P. R. (1983). Keyword in title indexes, effectiveness in retrieval in computer searchers. Special Libraries 74, 56-60.

Huth, E. J. (1999). Writing and publishing in medicine. Baltimore: Williams \& Wilkins.

Jacques T.S, \& N.J. Sebire (2010). The impact of article titles on citation hits and analysis of general and specialist medical journals. JRSM Short Report. June 30; 1(1), 2.

Jaime-Sisó, M. (2009) Titles or headlines? Anticipating conclusions in biomedical research article titles as a persuasive journalistic strategy to attract busy readers. Miscelánea: $A$ Journal of English and American Studies, 39, 29-54.

Jamali, H.R. \& Nikzad, M. (2011). Article title type and its relation with the number of downloads and citations. Scientometrics, 88 (2), 653-661.

Kerans, M.E, A. Murray \& Sergi Sabatè (2016). Content and phrasing in titles of original research and review articles in 2015: Range of practice in four clinical journals MDPI Publications. 4, 11; doi,10.3390/publications.4020011

Letchford, A., H. S. Moat \& T. Preis (2015). The advantage of short paper titles. Royal Society Open Science Publishing. Accessed March 26 ${ }^{\text {th }}$ 2015. http,//rsos.royalsocietypublishing.org/ content/royopensci/2/8/150266.full.pdf

Lewin, B.A. (2005). Hedging: an exploratory study of authors' and readers' identification of 'toning down' in scientific texts. Journal of English for Academic Purposes. 4, 163-178. 
Lewin, B.A. (2010). Writing readable research: A guide for students of social science. London: Equinox.

Lewison, G., \& Hartley, J. (2005). What's in a title? Number of words and the presence of colons. Scientometrics, 63, 341-356.

Lowes, R. (2016). PubMed asked to add conflict-of-interest info to abstracts Medscape. April 4th. http,//www.medscape.com/viewarticle/861440. Retrieved May 5th 2016.

Mabe, M.A., \& M. Amin (2002). Dr. Jekyll and Dr. Hyde: Author-reader asymmetries in scholarly publishing. Aslib Proceedings. 54(3), 149-157.

Maisonneuve, H., G. Lorette, A. Maruani,and M. Huguier (2010) La Rédaction Médicale. $5^{\circ}$ edition. France: Doin editeurs.

Mateen, F.J, J. Oh, A.I. Tergas, N.H. Bhayani, \& B.B. Kamdar (2013). Titles versus titles and abstracts for initial screening of article for systematic reviews. Clinical Epidemiology, 5, 8995.

Mayer, P. (2009) Guidelines for writing a review article. http,//www.plantscience.ethz.ch/ education/Masters/courses/Scientific_Writing.

Mendez, D.I., M.A. Alcaraz Ariza \& F. Salager-Meyer (2014). Titles in English-medium astrophysics research articles. Scientometrics. 98(3), 2331-2351. DOI, 10.1007/s11192-0131174-6.

Paiva, C.E, J.P. Lima, \& B.S. Paiva (2012). Articles with short titles describing the results are cited more often. Clinics (Sao Paolo). 67(5), 509-513.

Rosner, J.L. (1990). Reflections of science as a product. Nature, 345, 108.

Salager-Meyer, F. (1991). Medical English abstracts: How well are they structured? Journal of the American Society for Information Science, 42 (7), 538-531.

Salager-Meyer, F. (1994). Hedges and textual communicative function in medical English written discourse. English for Specific Purposes, 13(2), 149-171.

Salager-Meyer, F. (2014). Origin and development of English for medical purposes, Part I Medical Writing. 23(1), 49-52.

Salager-Meyer, F, M.A. Alcaraz Ariza \& M. Zambrano (2013). Titling and authorship practices in medical case reports: A diachronic study. Communication and Medicine, 10(1), 63-80.

Salager-Meyer, F, M.A. Alcaraz Ariza \& B. A. Lewin (2014). Abstract quality in complementary and alternative medicine papers, a structural and cross-generic analysis. In M. Bondi \& R. Lórez Sanz (Eds.). Abstracts in academic discourse: Variation and change. (pp. 221-243) Berne: Peter Lang.

Sharma. U. (2000). Medical pluralism and the future of CAM. In M. Kellner, B. Wellman, B. Pescosolido \& M. Sacks (Eds). Complementary and alternative medicine: Challenge and change. (pp. 211-222). Abington/New York: Routledge.

Smith, R. (2000). Informative titles in the BMJ. British Medical Journal, 320, 915. 
Soler, V. (2007). Writing titles in science: An exploratory study. English for Specific Purposes, 26(1), 90-102.

Soler, V. (2011). Comparative and contrastive observations on scientific titles in written English and Spanish. English for Specific Purposes, 30(2), 124-137.

Song, F., S. Parekh, L. Hooper, Y. K. Loke, Y.K. Ryder, A. J. Sutton, C. Hing, C.S. Kwok, C. Pang, \& I. Harvey. (2010). Dissemination and publication of research findings: An updated review of related biases. Health Technology Assessment. 14. Available online, https,//www.ncbi. nlm.nih.gov/pubmed/20181324. Accessed November 17, 2016.

Sword, H. (2012). Tempting titles. In H. Sword, (Ed.), Styling academic writing, (pp. 63-75). Cambridge, MA. \& London: Harvard University Press.

Teixeira Da Silva, J.A. (2015). Negative results, negative perceptions limit their potential for increasing reproducibility. Journal of Negative Results in Biomedicine. 14/12.

Vodanovic, M. (2015). Translation of titles: To be or not to be? European Science Editing, 41(4), 95.

Wang, Y., \& Bai, Y. (2007). A corpus-based syntactic study of medical research article titles. System, 35, 388-399.

Yadav, H. (2006). The philosophy of the medical case. Student BMJ 14, 133-176.

Yitzhaki, M. (1994). Relation of title length of journal articles to number of authors. Scientometrics, 30, 321-332.

Yitzhaki, M. (1997). Variations in informativity of titles of research papers in selected humanities journals: A comparative study. Scientometrics, 38(2), 219-229.

Yitzhaki, M. (2002). Relation of the title length of a journal article to the length of the article Scientometrics. 54(3), 435-447. 